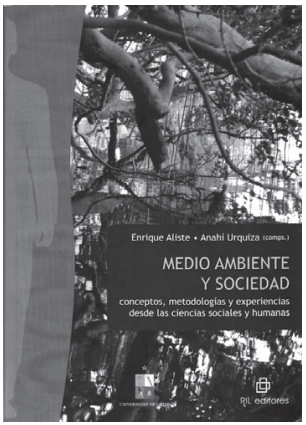

\title{
Enrique Aliste y Anahí Urquiza (comps.). Medio ambiente y sociedad. Conceptos, metodologías y experiencias desde las ciencias sociales y humanas
}

Santiago: RIL Editores, 2010. 273 p.

Abraham Paulsen ${ }^{1}$

En 273 páginas, tal como se adelanta en la página 15 de la presentación, se pretende "abordar la recomposición de la fracturada y fragmentada relación de la sociedad humana con la naturaleza". Tal objetivo, para su cumplimiento, requiere de dos condiciones, la primera, el abandono de las miradas tradicionales en pos de la transdiciplinariedad, que es probablemente la mayor fortaleza del texto, y la segunda, una selección de temas que sean oportunidades de aplicación de teorías, métodos y técnicas de las ciencias humanas y sociales. A nuestro juicio, esta segunda condición se cumple mayormente por el origen epistemológico de quienes escriben y los referentes desde los cuales parten, más que desde la aplicación de técnicas y métodos propios de las ciencias humanas y sociales. No es momento de discutir el problema de los métodos, pero nos parece que el texto también aporta interesantes insumos en esta materia. Volveremos sobre este aspecto más adelante.

Este libro empieza con una presentación redactada por el doctor Enrique Leff que introduce al lector en los aspectos que se tocan a lo largo de cada uno de los capítulos y se posiciona a la temática en la esencialidad de la obra del autor mexicano, el hecho de que la crisis ambiental es (o es también) una crisis social.

Entre las páginas 15 y 23 se incluye una introducción que explica las razones y oportunidades que se combinaron para redactar el libro. Se plantean algunos juicios que, al ser parte de una introducción, por estilo, no son fundamentados pero que aportan al inicio de la discusión acerca del modo y magnitud con las que las ciencias humanas y sociales se han preocupado del problema ambiental. Se señala, en la página 21 que "Ios esfuerzos de investigación y formación que vinculan al medio ambiente con las disciplinas que estudian la sociedad son poco frecuentes" y que "las disciplinas que estudian la sociedad han mostrado un escaso interés por el abordaje de este tema (el ambiental) como parte de su quehacer científico". Estos dos juicios dan para pensar y habría que reflexionar acerca de la madurez de los métodos con que tales problemáticas podrían realizar este tipo de estudios, toda vez que el tema ambiental está posicionado entre los que más preocupan a las sociedades contemporáneas y se relaciona con otros tan gravitantes tales como la inequidad distributiva, la sustentabilidad del desarrollo, el crecimiento económico, pobreza, participación ciudadana, democracia, entre otros.

A partir de la página 26 se incorpora al lector a una serie de estudios cuya temática es agrupada bajo el título de Conceptos, debates aproximaciones. Este segmento incluye cinco trabajos.

Respecto al primero, titulado Las amenazas ambientales: una visión desde la teoría de los sistemas sociopoiéticos, de Cathalifaud y Urquiza, constatamos cuatro aspectos que

\footnotetext{
1 Instituto de Geografía, Pontificia Universidad católica de Chile (Chile). E-mail: apaulsen@uc.cl
} 
deben ser considerados por el lector para obtener el mayor provecho posible de la lectura: (1) el enfoque, que sitúa a la problemática ambiental como una "catástrofe" (de hecho el título induce a lo mismo, cuando alude a "La amenaza" y el apartado VI se titula "Riesgo"). (2) También vinculado al enfoque, se trata de un trabajo con un énfasis de revisión y/o propuesta conceptual. (3) La crisis ambiental es tratada desde la existencia de "problemas de comunicación ambiental en la sociedad contemporánea", que se expresaría en la existencia de un "déficit cognitivo" que atenta contra el adecuado tratamiento y la visibilización social de los temas medioambientales, sobre todo en el contexto de las resonancias imperantes en las economías subdesarrolladas, mediatizadas por discursos imperantes y los puntos desde los cuales se construye el conocimiento, que generarían un modus operandi colonizador que influye decisivamente en las formas de construcción y comprensión de los temas ambientales. Y (4) recomendamos, la lectura detenida de la bibliografía ocupada por los autores; de este análisis se concluye en el aporte de la sociología para la edificación de conceptos tales como riesgo, amenaza, vulnerabilidad, catástrofe. Se extraña un análisis de tales conceptos desde la perspectiva de otras ciencias, tales como la geografía (que puede ser también considerada una ciencia social) y de las ciencias de la tierra o geociencias, que aun cuando no se ocupan de la sociedad como objeto de estudio, también realizan análisis que consideran aspectos asociados a los temas que se consignan en este capítulo. Destacamos el punto II, IV y VI; creemos que los planteamientos que nos presentan pueden ser especialmente aprovechados por un lector más especializado en los temas socioambientales.

El trabajo de Enrique Aliste titulado Territorio y Ciencias Sociales: Trayectorias espaciales y ambientales en debate, navega sobre uno de los conceptos fundantes de la geografía, el territorio. En el punto I se echa mano a una serie de aproximaciones, la mayoría proveniente de filósofos, sociólogos, arquitectos, sociólogos urbanos, geógrafos. Recomendamos la lectura del punto IV y relacionar sus contenidos con los planteamientos de Cathalifaud y Urquiza en materia de las resonancias y las colonialidades discursivas.
Este aspecto, sumado al tema desarrollado por Díaz y Morales, representan un valioso aporte metodológico para quienes busquen orientaciones para el abordaje de las problemáticas ambientales en países como el nuestro, las que también pueden inferir desde el estudio de casos presentado en la segunda parte de la obra.

El tercer trabajo de Díaz y Morales, titulado Tensiones entre lo global y lo local en el conflicto ambiental: posibilidades de observación del problema ambiental, apoyan los planteamientos epistemológicos consignados por los otros autores y se detienen en las escalas de análisis y cómo estas se influyen y afectan mutuamente.

Pilar Moraga y Luis Cordero nos presentan una serie de aportes en materia de derecho y legislación ambiental, los que son especialmente relevantes cuando asumimos nuestra condición de país en pañales donde aún las relaciones ser humano-sociedad y medio no tienen el techo legal que garantice una adecuada explotación de los recursos naturales considerando los derechos de los ciudadanos presentes y futuros. Sugerimos su lectura para quienes ha orientado recientemente sus inquietudes a estas temáticas.

La segunda parte del libro, titulada "Casos" contiene cuatro estudios que dan cumplimiento al objetivo de aplicación de teorías, objeto y método de las ciencias humanas y sociales: (1) "Construcción de imágenes e imaginarios litorales. Bases investigativas para promover sociedades litorales sustentables" de F. Ther; (2) "La gestación de la política ambiental minera antes de la $<<$ Revolución ambiental de los noventa $>>$ " de M. Folchi; (3) "Paradigmas del conocimiento y sistemas de gestión de los recursos hídricos: la gestión integrada de las cuencas hidrográficas", de J. Garcés. (4) "Nuevas formas de agencia social: de la visibilidad de los conflictos a la globalización de los objetos medioambientales", de A. Seguel. Recomendamos la lectura de este capítulo y su análisis en función de los conceptos de precaución, gobernabilidad, derechos e instituciones tratados previamente por Moraga y Cordero.

Cierra el libro con una presentación de los autores. 


\section{Consideraciones finales}

El texto Medio ambiente y Sociedad. Conceptos, metodologías y experiencias desde las ciencias sociales y humanas, de Enrique Aliste y Anahí Urquiza (comps.), contiene una gran riqueza conceptual y metodológica, la que se puede constatar desde la presentación de E. Leff hasta el tratamiento de cada uno de los casos presentados; los trabajos reseñados son esquemas investigativos que más que ser respuestas son indicios para buscar, mediante el uso de la observación atenta, nuevos nichos investigativos en los cuales aplicar los métodos de las ciencias humanas y sociales que permitan visibilizar y crear conciencia de los problemas ambientales que experimentan seres humanos y sociedades. Probablemente, la deuda metodológica que arrastran las ciencias humanas y sociales puede ser parcialmente saldada por trabajos como el aquí reseñado en cuya construcción confluyó la tan deseada asociación entre los estudios de casos y los paradigmas teóricos. En tal propósito también podría aportar la invitación al diálogo transdisciplinar e interdisciplinar a otras ciencias que, aun cuando no son propiamente ciencias sociales (como las ciencias de la tierra) abordan temas como los consignados en las páginas de este libro. 